\title{
Lateral location of placenta on ultrasound as a predictive test for preeclampsia
}

\author{
Ramya Kaku, Pradeep Shivaraju*, Vimala K. R., Krishna Lingegowda
}

Department of Obstetrics and Gynecology, PESIMER, Andhra Pradesh, India

Received: 19 December 2016

Accepted: 31 January 2017

\author{
*Correspondence: \\ Dr. Pradeep Shivaraju, \\ E-mail: drpradi@gmail.com
}

Copyright: () the author(s), publisher and licensee Medip Academy. This is an open-access article distributed under the terms of the Creative Commons Attribution Non-Commercial License, which permits unrestricted non-commercial use, distribution, and reproduction in any medium, provided the original work is properly cited.

\section{ABSTRACT}

Background: Hypertensive disorders represent the most common medical complication of pregnancy Pre-eclampsia complicates approximately $2-7 \%$ of pregnancies and is a major cause of maternal and perinatal morbidity This has led to the interest in screening. The placenta is located laterally in majority of patients with abnormal flow velocity waveforms. In the light of these observations, we designed a prospective study to find out whether the lateral location of placenta as seen by ultrasound at II and III trimester of gestation can be used to predict the development of preeclampsia.

Methods: A prospective observational study was done in PESIMSR, Kuppam, Andhra Pradesh. The aim of the study was to find out whether placental laterality as determined by ultrasound can be used as a predictor of development of gestational hypertension, development of preeclampsia/eclampsia During the study period of November 2013 to November 2014, all antenatal women attending the OPD in II and III trimester without any medical disorders like DM, HTN, renal disease, cardiac disease or smoking, who undergo ultrasound in II and III trimester were included. The location of the placenta was determined by real time ultrasound in II and III trimester. The placenta will be classified as central when it is equally distributed between the right and the left side of the uterus irrespective of anterior, posterior or fundal position. When $75 \%$ or more of the placental mass is to one side of the midline, it is classified as unilateral right or left placenta. subjects were followed upto delivery for development of gestational hypertension/ preeclampsia/eclampsia as per the ACOG criteria.

Results: 66\% patients in the lateral placenta group developed preeclampsia. Only 36\%in the central group developed preeclampsia. The association of lateral placenta as a predictor of preeclampsia had a $\mathrm{P}$ value of $<0.001$ which is statistically significant. Incidence of preclampsia is more in primigravidas compared to multigravidas. Most of the pre eclamptics had their onset at 29 - 32 weeks of gestation.

Conclusions: The study shows that placental position determined by ultrasonogram in II and III trimester of gestation is an excellent screening tool for the prediction of pre-eclampsia. The test is ideal because it is simple, non-invasive, cost effective and convenient to the women.

Keywords: Lateral placenta, Predictors of pre-eclampsia, Ultrasound in preeclampsia

\section{INTRODUCTION}

Hypertensive disorders represent the most common medical complication of pregnancy. It complicates up to $7-10 \%$ of pregnancies of which pre-eclampsia/ Eclampsia constitutes $70 \%$, and Chronic hypertension $30 \%{ }^{1}$ It is said that pre-eclampsia, eclampsia contributes to death of a woman every 3 minutes worldwide. ${ }^{2}$ Infants of women with severe Pregnancy induced hypertension have 5-fold increase in mortality compare to infants of normotensive women. $^{2}$ This has led to the interest in screening, in preventing this disorder the most important factor is lack 
of timely prediction. ${ }^{3}$ Non-invasive Doppler velocimetric studies of the uterine arteries in the second trimester reveal that abnormal wave forms indicating defective uterine perfusion is primarily a consequence of placental implantation when one uterine artery is the dominant supply of the intervillous flow.,

The placenta is located laterally in majority of patients with abnormal flow velocity waveforms. ${ }^{4}$ In the light of these observations, we designed a prospective study to find out whether the lateral location of placenta as seen by ultrasound at II and III trimesters of pregnancy can be used to predict the development of preeclampsia.

For a screening test to be of value, it should be sensitive, reliable, cheap and easy to perform. It should increase the predictive value and the prophylactic measures must be effective. ${ }^{5}$ The objective of present study was to find out whether placental laterality as determined by ultrasound can be used as a predictor of development of gestational hypertension, development of preeclampsia/eclampsia.

\section{METHODS}

The study was conducted at PESIMSR hospital from November 2013 to November 2014, all antenatal women fulfilling the inclusion criteria attending the OPD in II and III trimesters were recruited under the study. Pregnant women, without any medical disorders like DM, HTN, renal disease or cardiac disease who underwent ultrasound in II and III trimesters were included. BP was recorded at sitting position, Phase Korotkoff $\mathrm{V}$ sound was taken to determine the diastolic component. The location of the placenta was determined by real time ultrasound in II and III trimesters. The placenta was classified as central when it is equally distributed between the right and the left side of the uterus irrespective of anterior, posterior or fundal position. When $75 \%$ or more of the placental mass was to one side of the midline, it was classified as unilateral right or left placenta. Subjects were followed till delivery for development of gestational hypertension/ preeclampsia/eclampsia as per the ACOG criteria.

\section{Statistical analysis}

Chi square test was applied for statistical analysis of qualitative data. $\mathrm{P}<0.05$ was taken as statistically significant. Two tailed $\mathrm{Z}$ test was used for identification of significance in quantitative data. Statistical analysis was performed by using analytical tool pack of Microsoft Excel 2010.

\section{RESULTS}

Most of the antenatal mothers in the present study are in the age group of 20-25 years.

The relationship of maternal age and incidence of preeclampsia show higher incidence among young primigravida. In the study group preeclampsia was high between 20-25years.

Table 1: Distribution of persons in study group according to age.

\begin{tabular}{|l|l|l|l|}
\hline$<20$ years & $\begin{array}{l}\geq 20-25 \\
\text { years }\end{array}$ & $\begin{array}{l}\geq 25-30 \\
\text { years }\end{array}$ & $>30$ years \\
\hline 35 & 161 & 112 & 42 \\
\hline $10 \%$ & $46 \%$ & $32 \%$ & $12 \%$ \\
\hline
\end{tabular}

Table 2: Distribution of patients with preeclampsia according to age.

\begin{tabular}{|l|l|l|l|}
\hline 20 years & $\begin{array}{l}\geq 20-25 \\
\text { years }\end{array}$ & $\begin{array}{l}\geq 25-30 \\
\text { years }\end{array}$ & $\begin{array}{l}>30 \\
\text { years }\end{array}$ \\
\hline $49(26.2 \%)$ & $103(55 \%)$ & $35(18.7 \%)$ & 0 \\
\hline
\end{tabular}

Table 3: Distribution of patients with preeclampsia according to parity.

\begin{tabular}{|l|l|l|l|}
\hline Parity & Total & $\begin{array}{l}\text { Pre- eclampsia } \\
\text { positive }\end{array}$ & Percent \\
\hline Primigravida & 140 & 101 & $72 \%$ \\
\hline Multigravida & 210 & 86 & $28 \%$ \\
\hline
\end{tabular}

Table 3 shows the distribution of patients with preeclampsia according to parity. Preeclampsia is more common in primigravida. This table show high incidence of preeclampsia in primigravida (72\%) than in multigravida $(28 \%)$.

131 out of 196 antenatal mothers in the lateral placenta group, 56 out of 154 antenatal mothers in the central placenta group developed preeclampsia which accounted to $70 \%$ \& $30 \%$ respectively of all pre-eclamptics.

Table 4: Relationship of placental position and development of preeclampsia.

\begin{tabular}{|l|l|l|}
\hline $\begin{array}{l}\text { Placental } \\
\text { position }\end{array}$ & $\begin{array}{l}\text { Developed pre- } \\
\text { eclampsia }\end{array}$ & Normotensive \\
\hline Central (154) & $56(29.9 \%)$ & $98(60.1 \%)$ \\
\hline Lateral (196) & $131(70 \%)$ & $65(39.8 \%)$ \\
\hline
\end{tabular}

Table 5: Distribution of patients according to their first appearance of preeclampsia in weeks.

\begin{tabular}{|l|l|}
\hline Gestational age in weeks & Number of patients \\
\hline $26-30$ & $60(32.1 \%)$ \\
\hline$>30-34$ & $99(52.9 \%)$ \\
\hline$>34-38$ & $28(14.9 \%)$ \\
\hline
\end{tabular}

The Table 6 denotes that distribution of persons according to severity of preeclampsia in lateral placenta group. 64\% patients had mild preeclampsia, 20.6\% patients had moderate preeclampsia, $15 \%$ had severe preeclampsia. 
Table 7 shows that out of 196 antenatal mothers who had lateral placenta, 131 developed preeclampsia, and the $\mathrm{p}<0.001$ which is significant.

Table 6: Distribution of patients according to severity of preeclampsia in lateral placenta group.

\begin{tabular}{|l|l|}
\hline Type of pre-eclampsia & Study group \\
\hline Mild $(140 / 90-149 / 99)$ & $84(64 \%)$ \\
\hline Moderate $(150 / 100-160 / 109)$ & $27(20.6 \%)$ \\
\hline Severe $(>160 / 110)$ & $20(15 \%)$ \\
\hline
\end{tabular}

Table 7: Probability value of placental position in predicting preeclampsia.

\begin{tabular}{|l|l|l|}
\hline $\begin{array}{l}\text { Placental } \\
\text { position }\end{array}$ & $\begin{array}{l}\text { Developed } \\
\text { preeclampsia }\end{array}$ & Normotensive \\
\hline Central (196) & $131(70 \%)$ & $65(39.9 \%)$ \\
\hline Lateral (154) & $56(29.9 \%)$ & $98(60.1 \%)$ \\
\hline
\end{tabular}

\section{DISCUSSION}

Preeclampsia is a complex clinical syndrome involving multiple organ systems and remains the principal cause of maternal and perinatal morbidity and mortality. ${ }^{6}$ Unfortunately, there has been little progress in predicting the disorder compared to advances made in eliminating other serious medical conditions. The magnitude of the problem and the impact on the mother and the neonate need to be highlighted and updated especially in developing countries where the incidences are high. Unless effective prevention strategies are developed and implemented, the huge cost of critical care for the mother, the newborn and the long term problems in the premature or intrauterine growth restricted baby will continue to impact on health systems. ${ }^{7}$ The search for an ideal predictive test and preventive measures remains challenging However, whether placenta is laterally located, in the majority of the cases, the uteroplacental blood flow needs are met primarily by one of the uterine arteries with some contribution from the other uterine artery via the collateral circulation. ${ }^{4}$ The degree of collateral circulation may not be the same in all the women and deficient contribution may facilitate the development of preeclampsia, the results of the present study were comparable to those of Muralidhar et al. ${ }^{8}$ In his study, a total of 426 unselected singleton pregnant women were included. Out of 426 women, 324 had centrally located placenta and 102 had unilateral placenta. A total of 71 women developed preeclampsia of which 52 (74\%) had unilaterally located placenta. The relationship was found to be statistically significant $p<0.0001$. In the present study $66 \%$ of lateral placenta developed preeclampsia and the relationship was found to be statistically significant $\mathrm{p}<0.001$. The results are comparable to the study done by Lucy et al. ${ }^{9}$ The results of which showed that development of PIH and IUGR pregnancies were nearly fourfold more in lateral placentation. In the present study, there is two-fold increase in the development of pre-eclampsia. The results of present study are close to the study done by Bhalerao AV et al, who stated that ultrasonography in pregnant women during 20-24 weeks of gestation can be a ease, noninvasive, useful and cost-effective tool as a predictor ofpreeclampsia. ${ }^{10}$ Futhermore, results are also comparable to the investigations done by Kakkar et al in which out of the total 150 women, $84(56 \%)$ had laterally located placenta and of them, $56(66.6 \%)$ developed preeclampsia, while the remaining $66(44 \%)$ had centrally located placenta and of them, 24 (36.3\%) developed preeclampsia. $^{11}$

\section{CONCLUSION}

The study shows that placental position determined by ultrasonogram in II and III trimesters of gestation is an excellent screening tool for the prediction of preeclampsia. The test is ideal because it is simple, noninvasive, cost effective and convenient to the women since ultrasound examination is a part of routine antenatal care. The magnitude of the problem and the impact on the mother and the neonate need to be highlighted and updated especially in developing countries where the incidences are high. In addition to the immediate burden, there are long term consequences of the disease. Unless effective prevention strategies are developed and implemented, the huge cost of critical care for the mother, the newborn and the long-term problems in the premature or intrauterine growth restricted baby will continue to impact on health systems. ${ }^{12}$

\section{Funding: No funding sources}

Conflict of interest: None declared

Ethical approval: The study was approved by the Institutional Ethics Committee

\section{REFERENCES}

1. Queenan JT, Spong CY, Lockwood CJ. Protocols for high risk pregnancies: An Evidence-Based Approach. 6th ed. Wiley-Blackwell, 2015.

2. Vidyadhar B, Bangal, Giri PA, Mahajan AS et al. Maternal and foetal outcomes in Pregnancy Induced Hypertension -a hospital based study. 2011.

3. Walker JJ. Current thoughts on the pathophysiology of preeclampsia/eclampsia. In: John Studd (ed). Progress in Obstetrics and Gynecology, Edinburgh. Churchill-Livingstone; 1998: 177-88.

4. Fleischer A, Schulman H, Farmakides G, Bracero L, Grunfeld L, Rochelson B et al. Uterine artery Doppler velocimetry in pregnant women with hypertension. Am J Obstet \& Gynecol. 1986;154:806-13.

5. Schulman H, Winter D, Farmakides G, Ducey J, Guzman E, Coury A et al. Pregnancy surveillance with Doppler velocimetry of uterine and umbilical arteries. Am J Obstet Gynecol. 1989;160:192-6.

6. English FA, Kenny LC, McCarthy FP. Risk factors and effective management of preeclampsia. Integr Blood Press Control. 2015;8:7-12. 
7. Gulher Sahin, Gulmezoglu AM. Incidence morbidity and mortality of preeclampsia and eclampsia. Geneva Foundation for Medical Education and Research. 2003.

8. Muralidhar PV, Jyothi P. Placental lateriality by ultrasound-a simple yet reliable predictive test for preeclampsia. J Obstet Gynecol India. 2005;55:4313.

9. Bramham K, Briley AL, Seed P, Poston L, Shennan $\mathrm{AH}$, Chappell LC. Adverse maternal and perinatal outcomes in women with previous preeclampsia: a prospective study. Am J Obstet Gynecol. 2011; 204(6):512e1-9.

10. Bhalerao AV, Kukarni S, Somalwar S, 2013. Lateral placentation by ultasonography: a simple predictor of preeclampsia. J South Asian Feder Obst Gynae. 2013;5(2):68-71.

11. Patel A, Dabhadkar S, Taralekar V, Wagh G. 2012. Placental Laterality and Uterine Artery Resistance for Prediction of preeclampsia. Indian J of App Res. 2012;2:118-9.

12. Venkataramana S, Padmaja G. Placentral Laterality by Ultrasound- a simple yet reliable predictive test for pre-eclampsia. Indian J of App Res. 2015;5:77880.

Cite this article as: Kaku R, Shivaraju P, Vimala K $\mathrm{R}$, Lingegowda $\mathrm{K}$. Lateral location of placenta on ultrasound as a predictive test for preeclampsia. Int J Reprod Contracept Obstet Gynecol 2017;6:930-3. 